\title{
When Satisfaction with Work-family Balance Pays
}

\author{
Sowon $\mathrm{Kim}^{1}$, Mireia Las Heras ${ }^{2}$, Pablo I. Escribano ${ }^{2}$ \\ ${ }^{1}$ Ecole hôtelière de Lausanne, HES-SO, University of Applied Sciences Western Switzerland, Switzerland \\ ${ }^{2}$ IESE Business School, Universidad de Navarra, Barcelona, Spain \\ Correspondence: Mireia Las Heras, IESE Business School, Universidad de Navarra, Pearson Avenue 21, \\ Barcelona 08034, Spain. E-mail: mlasheras@iese.edu
}

Received: June 12, 2016

doi:10.5539/ibr.v9n11p178
Accepted: June 28, $2016 \quad$ Online Published: October 17, 2016

URL: http://dx.doi.org/10.5539/ibr.v9n11p178

\begin{abstract}
This study examines the mechanism through which family supportive environments in organizations (i.e. family supportive supervisor behaviors and work-family friendly culture) relate to turnover intentions. In a sample of 340 individuals, analysis using structural equation modeling showed that satisfaction with work-family balance mediates the relation between family supportive environments in organizations and turnover intentions. Thus, family supportive environments in organizations facilitate greater satisfaction with work-family experiences, which, in turn, relates with lower intentions to leave the company. We discuss research and practical implications of this study.
\end{abstract}

Keywords: work-family interface, family supportive supervisor behaviors, work-family friendly culture, satisfaction with work-family balance, turnover intentions

\section{Introduction}

Work and family balance has become a central element for individuals, organizations and societies as a result of a large influx of women joining the workforce in the second half of the 20th century. Work and family balance has a significant impact on physical and psychological health, organizational outcomes, family relations, and childbirth rates among other relevant outcomes in industrialized societies (e.g. Pitt-Catsouphes, Kossek, \& Sweet, 2006; Poelmans, Greenhaus, \& Las Heras, 2013). On the other hand, work-family conflict leads to negative outcomes such as lower job satisfaction and job performance and higher stress, psychological problems, absenteeism and turnover (e.g. Bruck, Allen, \& Spector, 2002; van Steenbergen \& Ellemers, 2009). Therefore, an increasing number of organizations have become family supportive by promoting a family friendly corporate culture and encouraging family friendly behaviors from their managers.

Work-family friendly culture refers to the shared assumptions, beliefs, and values regarding the extent to which the organization supports and values the integration of employees' work and family lives (Thompson, Beauvais, \& Lyness, 1999). Family supportive supervisor behaviors (FSSB) (Hammer, Kossek, Yragui, Bodner, \& Hanson, 2009) are those that facilitate the use of work-family policies by employees (Casper, Fox, Siztmann, \& Landy, 2004; Kelly \& Kalev, 2006) and increase subordinates' resources, skills and perspectives while promoting flexibility (Matthews, Mills, Trout, \& English, 2014). FSSBs promote work-family balance (McCarthy, Cleveland, Hunter, Darcy, \& Grady, 2013) and decrease work-family conflict (Barrah, Schultz, Baltes, \& Stolz, 2004; Frye \& Breaugh, 2004).

Employees who work in family supportive environments are likely to have a lower desire to leave the organization (Odle-Dusseau, Hammer, Crain, \& Bodner, 2016), thus attenuating the potential costs associated with turnover. Research reveals that turnover intentions predict actual turnover (Batt \& Valcour, 2003; Behson, 2005; Maertz, Griffeth, Campbell, \& Allen, 2007).

Our paper contributes to the understanding of the mechanisms through which family supportive behaviors and family supportive cultures in organizations result in lower turnover intentions. A simplistic view of the impact of FSSB and family supportive cultures in organizations is likely to lead to erroneous implementations, negative consequences, and misleading conclusions. On the other hand, understanding the mechanisms through which family supportive behaviors and family supportive cultures lead to positive outcomes is bound to enhance the positive consequences of supportive behaviors and cultures. 


\section{Social Exchange Theory}

We base our study on social exchange theory - SET (Blau, 1964; Emerson, 1976; Gouldner, 1960; Homans, 1958). SET puts a great emphasis on the interaction between people, and the positive vs. negative reactions toward each other. SET posits that social interactions depend on the rewards (and costs) that the exchanges imply. Social behavior requires and involves an exchange, that is, a give-and-take relationship. Blau (1964) suggests that economic and social exchange are intrinsically different from each other; while economic exchange is situated within strict contracts or agreements, social exchange exists outside strict contracts. Social exchange relationships go beyond tangible or quantifiable rewards to include exchanges of socially relevant rewards. Examples are social status and recognition in exchange for loyalty, commitment, and involvement. Moreover, these exchanges are dynamic in nature, i.e. for social exchanges to happen they should satisfy both participants to ensure the maintenance of the interaction process. For instance, the paper by Lambert (2000) links work-life benefits and organizational citizenship behavior conceptualizing them as intangible currencies in an employer-employee exchange. According to Lambert, social exchange theory implies that workers may feel obligated to exert "extra" effort in return for "extra" work-family benefits.

Social exchange theory is an appropriate framework to justify the relationships in our model because, first, it offers a rationale to understand the social exchange involved in the desire to remain involved in a work relationship, i.e. lower turnover intentions. Second, it offers a framework to think about the interaction between supervisor support and outcomes, as a dyadic relationship. Third, it makes it possible to consider multiple relationships simultaneously, which is very relevant when considering the outcomes of culture.

In our paper, based on SET, we postulate that individuals whose lives are more balanced due to support from their organizations and managers, are less likely to be willing to leave their companies. We define work-family balance as "the extent to which an individual is equally engaged in - and equally satisfied with - his or her work role and family role" (Greenhaus, Collins, \& Shaw, 2003). Satisfaction with work family balance (SWFB) is composed of three dimensions: time (an equal amount of time dedicated to work and family roles), involvement (an equal level of psychological involvement in work and family roles) and satisfaction (an equal level of satisfaction with work and family roles). In this study, we focus particularly on SWFB (Clark, 2000; Valcour, 2007) because satisfaction results from the perception that time and involvement spent in each role is adequate (Greenhaus et al., 2003). Our study examines the mediating effect of SWFB on (a) FSSB and (b) work-family friendly culture and turnover intentions.

Our study contributes to the work-family literature mostly in two ways. First, it increases the theoretical understanding of the antecedents and consequences of SWFB (Valcour, 2007). SWFB is conceptually different (Greenhaus et al., 2003) from constructs that focus on the positive effects of the work-family interface, i.e. work-family enrichment (Greenhaus \& Powell, 2006), facilitation (Wayne, Grzywacz, Carlson, \& Kacmar, 2007) and enhancement (Ruderman, Ohlott, Panzer, \& King, 2002). In comparison to the other constructs in the literature, SWFB is underrepresented in research although it has been widely cited in the popular press. Second, our study sheds light on the mechanism through which supportive environments lower turnover intentions, we underline the importance of focusing on the specific needs of the employees, rather than offering policies that might not solve their actual need for flexibility.

\section{Theory and Hypothesis}

\subsection{Family Supportive Environments and Satisfaction with Work-family Balance}

We define family supportive environments as those in which managers display FSSB and have a work-family friendly culture. FSSB consist of behaviors displayed by managers that aim to provide emotional support, instrumental support, role modeling, and creative work-family management in order to facilitate employee effectiveness on and off the job (Hammer, Kossek, Zimmerman, \& Daniels, 2007). Because supervisors act as gatekeepers over the types and amount of family support that employees receive (den Dulk \& de Ruijter, 2008; McCarthy, Darcy, \& Grady, 2010), supervisors impact employees' work-family balance (McCarthy et al., 2013). Supervisor supportiveness associates with employees' capacity to manage work and family issues, which in turn decreases anxiety, depression (Snow, Swan, Raghavan, Connell, \& Klein, 2003), and work-family conflict (Breaugh \& Frye, 2008; Lapierre \& Allen, 2006). FSSB relate to an increase in loyalty to the organization (P. Roehling, M. Roehling, \& Moen, 2001) as well as use of work-family policies (Blair-Loy \& Wharton, 2004; Kalev, Dobbin, \& Kelly, 2006).

Work-family friendly culture refers to the shared assumptions, beliefs, and values regarding the extent to which the organization supports and values the integration of employees' work and family lives (Thompson et al., 1999). A work-family friendly culture does not necessarily require work-family policies to be in place; yet, it 
comprises initiatives aimed to better balance both roles. Actually, work-family policies per se do not automatically decrease work-family conflict. Empirical evidence shows inconclusive results ranging from a negative relationship between policies and work-family conflict (e.g. Allen, 2001; Mennino, Rubin, \& Brayfield, 2005), to no relationship (e.g. Batt \& Valcour, 2003; Kossek, Lautsch, \& Eaton, 2006) and even to a positive relationship (e.g. Brough, O'Driscoll, \& Kalliath, 2005; Hammer, Neal, Newsom, Brockwood, \& Colton, 2005). These inconclusive findings point to the fact that the results of implementing policies depend on the extent to which the organizational culture actually favors employees' balance between work and family lives (Ryan \& Kossek, 2008; Thompson, 2008). Thus, we postulate that,

Hypothesis 1: FSSB will positively relate to satisfaction with work-family balance.

Hypothesis 2: Work-family friendly culture will positively relate to satisfaction with work-family balance.

\subsection{Satisfaction with Work-family Balance and Turnover Intentions}

The concept of turnover intentions refers to the desire to leave the organization (Tett \& Meyer, 1993). Employees working for family-supportive supervisors, who do not require employees to consistently put work before family nor spend a disproportionate amount of time at work, have lower turnover intentions (O'Neill et al., 2009). Likewise, the perception of family supportive environments in organizations decreases work-family conflict and turnover intentions, and it increases job satisfaction and organizational commitment (Allen, 2001). Maertz and colleagues (2007) examined the mediating effects of both perceived supervisor support and perceived organizational support on turnover cognitions and their interactive effects on turnover behaviors. While perceived supervisor support influenced turnover cognitions, perceived organizational support had an impact on turnover behaviors. Hence, organizations that (a) foster environments where employees have work autonomy and (b) have family-supportive supervisors have more satisfied employees who experience less stress, less workfamily conflict, and have lower turnover intentions (Behson, 2005). We postulate that the higher the SWFB, the lower the intention to leave the organization.

Hypothesis 3: Satisfaction with work-family balance is associated with lower turnover intentions.

\subsection{The Mediating Role of Satisfaction with Work-family Balance}

As we seek to understand the mechanism through which FSSB and work-family friendly culture relate to turnover intentions we examined the mediating role of SWFB. Social exchange theory explains that individuals tend to interact in the aim of obtaining valued resources (Homans, 1958). A positive action that an individual makes today raises the expectation of a future return even though it may be unclear when and how this favor will be reciprocated (Blau, 1964; Gouldner, 1960). Thus, a series of positive interactions generate obligations (Emerson, 1976) as people involved in the interaction expect reciprocity (Cropanzano \& Mitchell, 2005). We thus hypothesize that individuals who, as a result of the support from their supervisors and organizations, are more satisfied with their work and family balance, are more likely to be willing to contribute to their companies and thus less likely to leave them.

Hypothesis 4: Satisfaction with work-family balance will mediate the negative relation between FSSB and turnover intentions.

Hypothesis 5: Satisfaction with work-family balance will mediate the negative relation between work-family friendly culture and turnover intentions.

\section{Method}

\subsection{Participants and Procedure}

We collected data as part of a larger project on work-family conciliation. Members of the International Center for Work and Family at a Spanish University contacted individuals from multinational companies operating in Argentina and offered them the opportunity to participate in the study. In exchange, managers were offered a complete analysis reporting the degree to which practices for balancing work, family and personal life have been implemented in their company and future steps that can be taken to improve (or sustain) their actual condition. The survey was web-based and located on a secure server at the university. Participation was voluntary and the confidentiality of the respondents was ensured.

In total, we invited 665 individuals to participate in our study. After excluding missing data, our final sample consisted of 340 individuals. In this final sample, $53.2 \%$ were male (46.8\% female) and the mean age was 33.9 (SD $=7.1$ ) years old. Most of the employees reported that they had earned a bachelor's degree $(52.1 \%)$, did not have managerial responsibilities $(55.3 \%)$, were married or cohabiting $(72.1 \%)$, and had at least one child (53.5\%). Respondents worked in three multinational corporations $(\mathrm{n} 1=100, \mathrm{n} 2=114, \mathrm{n} 3=126)$, all from the service sector. 


\subsection{Measures}

We used validated existing measures at the individual level. All items used a 7-point Likert scale $(1=$ strongly disagree and $7=$ strongly agree). When measures were available in Spanish, we used those scales; otherwise, we translated original scales to Spanish using the back translation method (Brislin, 1970). In order to ensure conceptual equivalence, a team of experts validated the appropriateness of the translation (Harzing, Reiche, \& Pudelko, 2012).

\subsubsection{Independent Variables}

Independent variables were (a) FSSB and (b) work-family friendly culture. Family supportive supervisor behavior was measured using four items from the Hammer and colleagues (2009) scale. A sample item was "My supervisor is willing to listen to my problems in juggling work and non-work life" and this scale reported a reliability of .93 in our study.

We measured work-family friendly using four items referring to organizational time expectations that may interfere with family responsibilities from a scale developed by Thompson and colleagues (1999). A sample item was "To get ahead at this organization, employees are expected to work more than 50 hours a week, whether at the workplace or at home". Because this scale is negatively worded - reflecting an unfriendly work-family culture - we inverted the responses before analyzing the data. This scale reported a reliability of .87 in our study.

\subsubsection{Dependent Variables}

Dependent variables were (a) SWFB and (b) turnover intentions. We measured SWFB using three items from a scale developed by Valcour (2007). A Sample item was "I am satisfied with the way my personal and family life fit together" and this scale reported a reliability of .95 in our study.

We measured turnover intentions using three items from a scale developed by O'Reilly and colleagues (1991). A sample item was "I frequently think of quitting my job" and this scale reported a reliability of .88 in our study.

\subsubsection{Construct Validity}

Before we tested our hypothesized model, we followed two methods for testing the discriminant validity of the constructs. First, we conducted an exploratory factor analysis (EFA) to define the underlying structure of the items. Results (Eigenvalues $>1.0$, varimax orthogonal rotation) produced four factors where all the items loaded on the expected factors (primary loadings $=.73-.93$; highest cross loading $=.22$; variance explained $=80.49 \%$ ).

Second, to examine the discriminant validity of the four constructs in our study, we conducted a confirmatory factor analysis (CFA). We ran a maximum likelihood estimation in STATA 12.0 (StataCorp, 2011). We started by examining a 4-factor model in which all 4 factors loaded onto separate factors. We compared this 4-factor model with four alternative models. Those include (a) a 3-factor model where FSSB and work-family friendly culture loaded onto a single latent factor. (b) A 3-factor model where FSSB and SWFB loaded onto a single latent factor. (c) A 2-factor model where FSSB, work-family friendly culture, and SWFB loaded onto a single latent construct. (d) A 1-factor model where all the items loaded onto a single latent factor. We summarize the results in Table 1.

Table 1. Confirmatory Factor Analysis of Nested Models ( $\mathrm{N}=340$ )

\begin{tabular}{lllllllllll}
\hline Model & Description & chi-square & $\mathrm{df}$ & RMSEA & CFI & TLI & SRMR & $\Delta$ chi-square & $\Delta$ df & sig \\
\hline Model 1 & 4-factor model & 129.13 & 71 & .049 & .984 & .980 & .034 & & & \\
Model 2 & 3-factor model & 897.96 & 74 & .181 & .778 & .727 & .149 & 768.83 & 3 & .000 \\
Model 3 & 3-factor model & $1,188.67$ & 74 & .210 & .700 & .631 & .157 & $1,059.54$ & 3 & .000 \\
Model 4 & 2-factor model & $1,943.42$ & 76 & .269 & .497 & .398 & .206 & $1,814.30$ & 5 & .000 \\
Model 5 & 1-factor model & $2,457.56$ & 77 & .302 & .359 & .243 & .224 & $2,328.43$ & 6 & .000 \\
\hline
\end{tabular}

Notes:

Comparisons were made with Model 1.

RMSEA = root mean square error of approximation; CFI = comparative fit index; TLI = Tucker-Lewis index; SRMR $=$ standardized root mean square residual.

Model 1: All 4 factors loaded separately.

Model 2: Family supportive supervisor behaviors and work-family friendly culture loaded onto a single latent factor.

Model 3: Family supportive supervisor behaviors and satisfaction with work-family balance loaded onto a single latent factor.

Model 4: Family supportive supervisor behaviors, work-family friendly culture, and satisfaction with work-family balance loaded onto a single latent factor. 
Model 5: All the items loaded onto a single latent factor.

Results of the CFA show that our hypothesized 4-factor model showed a good fit with the data [chi-square $(71)=$ 129.125; $\mathrm{p}<.001 ; \mathrm{RMSEA}=.049 ; \mathrm{CFI}=.984 ; \mathrm{TLI}=.980 ; \mathrm{SRMR}=.034]$ and that it fits the data significantly better than the rest of the models. Thus, it indicates that the four factors included in our study are in fact distinct latent constructs.

\section{Results}

Table 2 presents descriptive statistics, zero order correlations, and reliabilities for the variables included in our study. As expected, in terms of correlations FSSB and work-family friendly culture are positively related to SWFB, which was negatively related to turnover intentions. Also in line with our reasoning, FSSB and work-family friendly culture were negatively related to turnover intentions.

Table 2. Means, Standard Deviations, Correlations, and Cronbach's Alpha (N=340)

\begin{tabular}{|c|c|c|c|c|c|c|c|}
\hline & Variable & $\mathrm{M}$ & SD & 1 & 2 & 3 & 4 \\
\hline 1 & Family Supportive Supervisor Behaviors & 5.75 & 1.22 & $(.929)$ & & & \\
\hline 2 & Work-Family Friendly Culture & 5.58 & 1.49 & $263 * *$ & $(.867)$ & & \\
\hline 3 & Satisfaction With Work-Family Balance & 4.68 & 1.43 & $.198^{* *}$ & $.231 * *$ & $(.952)$ & \\
\hline 4 & Turnover Intentions & 3.06 & 1.78 & $-.282 * *$ & $-.311 * *$ & $-.371 * *$ & $(.880)$ \\
\hline \multicolumn{8}{|c|}{ Cronbach's alpha on diagonal } \\
\hline \multicolumn{8}{|c|}{$* * \mathrm{p}<.01 ; * \mathrm{p}<.05$} \\
\hline & Iodel Specification & & & & & & \\
\hline
\end{tabular}

We tested the hypotheses simultaneously in order to enhance the statistical power of our conclusions involving mediating mechanisms. Therefore, we used structural equation models for testing the model we have hypothesized (Iacobucci, Saldanha, \& Deng, 2007). Accordingly, we compared four alternative nested models to examine the fit of the structural models. Model 1 is the more parsimonious structural model. In this model, SWFB fully mediated the relationships between FSSB and work-family friendly culture on turnover intentions. In Model 2, SWFB fully mediated the relationship between work-family friendly culture and turnover intentions and partially mediated the relationship between FSSB and turnover intentions. In Model 3, SWFB partially mediated the relationship between work-family friendly culture and turnover intentions and fully mediated the relationship between FSSB and turnover intentions. Finally, in Model 4, SWFB partially mediated the relationships between FSSB and work-family friendly culture on turnover intentions. These four models were estimated using Stata 12 and compared on the basis of mediation analysis procedures suggested by Iacobucci and colleagues (2007).

In Model 2, in which SWFB fully mediated the relationship between work-family friendly culture and turnover intentions and partially mediated the relationship between FSSB and turnover intentions, the direct effect of FSSB on turnover intentions was significant $(\mathrm{p}<.001)$. FSSB $(\mathrm{p}<.05)$ and work-family friendly culture $(\mathrm{p}$ $<.001)$ relates to SWFB. SWFB was significantly related to turnover intentions $(\mathrm{p}<.001)$. Additionally, the Sobel test of mediation was significant $(p<.05)$. Thus, the results suggest that the relationship between FSSB and turnover intentions is partially mediated by SWFB in this model.

Similarly, In Model 3, in which SWFB partially mediated the relationship between work-family friendly culture and turnover intentions and fully mediated the relationship between FSSB and turnover intentions, the direct effect of work-family friendly culture on turnover intentions was significant $(\mathrm{p}<.001)$. FSSB $(\mathrm{p}<.05)$ and work-family friendly culture $(\mathrm{p}<.001)$ was significantly related to SWFB, and SWFB was significantly related to turnover intentions $(\mathrm{p}<.001)$. Additionally, the Sobel test of mediation was significant $(\mathrm{p}<.001)$. Therefore, these results suggest that the relationship between work-family friendly culture and turnover intentions is partially mediated by SWFB in this model.

Finally, in Model 4, in which SWFB partially mediated the relationships between FSSB and work-family friendly culture on turnover intentions, the direct effect of FSSB $(p<.001)$ and work-family friendly culture $(p<.01)$ on turnover intentions was significant, FSSB $(p<.05)$ and work-family friendly culture $(p<.001)$ were significantly related to SWFB, and SWFB was significantly related to turnover intentions $(\mathrm{p}<.001)$. Moreover, the Sobel test of mediation was significant for the case of FSSB $(p<.05)$ as well as for work-family friendly culture $(p<.001)$. Therefore, SWFB partially mediates the relationships between FSSB and work-family friendly culture on turnover intentions in this model. Table 3 shows fit indices and results of the test of our structural models. 
Table 3. Competing Models $(\mathrm{N}=340)$

\begin{tabular}{|c|c|c|c|c|c|c|c|c|c|c|c|c|c|}
\hline \multirow[b]{2}{*}{ Model } & \multirow[b]{2}{*}{ Description } & \multirow[b]{2}{*}{ chi-square } & \multirow[b]{2}{*}{ df } & \multirow[b]{2}{*}{ RMSEA } & \multirow[b]{2}{*}{ CFI } & \multirow[b]{2}{*}{ TLI } & \multirow[b]{2}{*}{ SRMR } & \multicolumn{3}{|c|}{ Change from Model 1} & \multicolumn{3}{|c|}{ Change from Model 2} \\
\hline & & & & & & & & $\Delta$ chi-square & $\Delta \mathrm{df}$ & sig & $\Delta$ chi-square & $\Delta \mathrm{df}$ & sig \\
\hline Model 1 & Full Mediation & 159.76 & 73 & .059 & .977 & .971 & .081 & & & & & & \\
\hline Model 2 & Partial Mediation & 139.71 & 72 & .053 & .982 & .977 & .051 & 20.05 & 1 & .000 & & & \\
\hline Model 3 & Partial Mediation & 142.18 & 72 & .054 & .981 & .976 & .053 & 17.58 & 1 & .000 & & & \\
\hline Model 4 & Partial Mediation & 129.13 & 71 & .049 & .984 & .980 & .034 & 30.63 & 2 & .000 & 10.58 & 1 & .001 \\
\hline
\end{tabular}

Notes: Models 2, 3, and 4 were compared to Model 1. Model 4 was also compared to Model 2.

RMSEA = root mean square error of approximation; CFI = comparative fit index; TLI = Tucker-Lewis index; $\mathrm{SRMR}=$ standardized root mean square residual

Model 1: Family supportive supervisor behaviors full mediation, work-family friendly culture full mediation.

Model 2: Family supportive supervisor behaviors partial mediation, work-family friendly culture full mediation.

Model 3: Family supportive supervisor behaviors full mediation, work-family friendly culture partial mediation.

Model 4: Family supportive supervisor behaviors partial mediation, work-family friendly culture partial mediation.

Because Model 4 is the only one with a strong goodness of fit [RMSEA $=.049 ;$ CFI $=.984$; TLI $=.980$; SRMR $=.034]$ and because, compared to the rest of the models, the differences in chi-square were significant, we concluded that Model 4 fits the data significantly better than the rest of the models. Therefore, we retained Model 4, the least parsimonious model, in which SWFB partially mediated the relationship between both FSSB and work-family friendly culture, and turnover intentions. Figure 1 presents the standardized estimates in the final structural model.

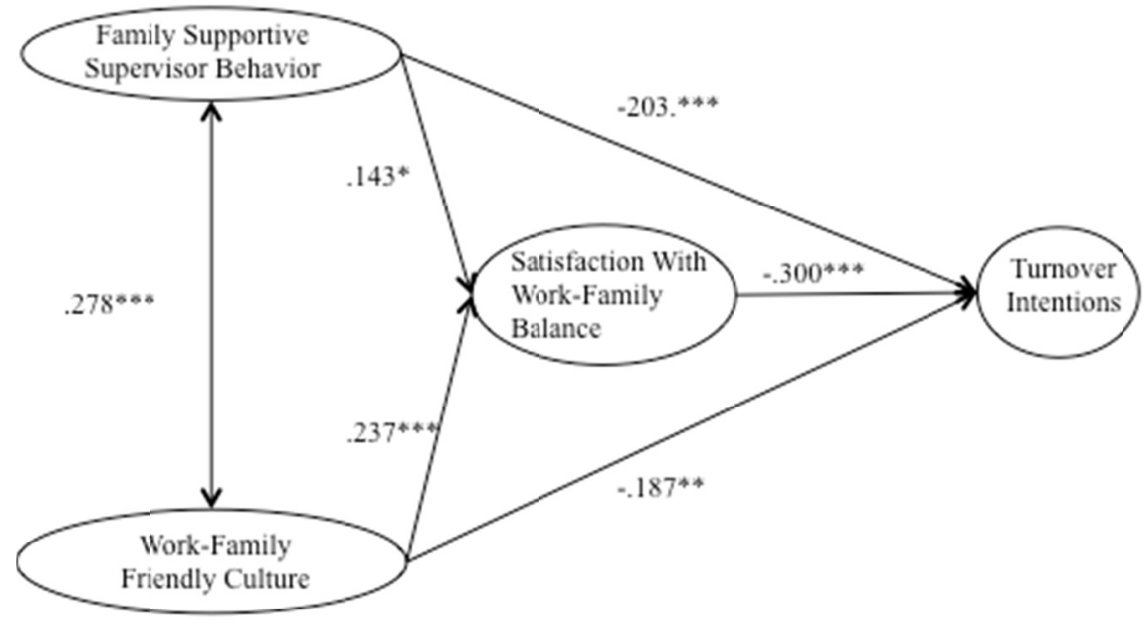

Note: Path estimates are standardized coefficients.

${ }^{*} \mathrm{p}<.05 ;{ }^{* *} \mathrm{p}<.01 ;{ }^{* 6 \mathrm{~s}} \mathrm{p}<.001$

Figure 1. Model Estimate

\subsection{Testing Hypotheses for Direct Effects}

Hypotheses 1 and 2 focused on aspects of the organizational context that foster SWFB. Both hypotheses are supported by our data. FSSB $(\beta=.143, \mathrm{p}<.05)$ and work-family friendly culture $(\beta=.237, \mathrm{p}<.001)$ are positively related to SWFB. Hypothesis 3 focused on the relationship between SWFB and the intentions to leave the organization. Hypothesis 3 is supported since SWFB is negatively related to turnover intentions $(\beta=-.300, p$ $<.001$ ). Thus, all our hypotheses regarding direct relationships (hypothesis 1 to hypothesis 3 ) are supported.

\subsection{Testing Hypotheses for Mediating Mechanisms}

Hypotheses 4 and 5 focused on the mediating role of SWFB in our model. As displayed in Figure 1, FSSB and work-family friendly culture predicted both SWFB and turnover intentions, while the relationship between satisfaction and work-family balance and turnover intentions remains significant, as well. Because those relationships are significant, and the Sobel test of mediation is significant for the case of FSSB $(p<.05)$ as well as 
for work-family friendly culture $(\mathrm{p}<.001)$, we can conclude that SWFB partially mediates the relationships between FSSB and work-family friendly culture on turnover intentions. Hence, hypotheses 4 and 5 are supported.

\subsection{Assessment of Common Method Bias}

The use of self-reports and a single wave for gathering survey data raises the possibility that our results may be affected by common method bias (CMB) (P. Podsakoff, MacKenzie, Lee, \& N. Podsakoff, 2003). Therefore, it is important to test whether a systematic source of variance related to our research design might be inflating the results. Accordingly, to assess this possible inflating effect we followed two different procedures. First, we conducted a Harman's single factor test (Podsakoff, 1986). In this test, all the variables in our study are introduced into an exploratory factor analysis and examine the unrotated factor solution to determine the number of factors that are necessary to account for the variance in the variables. CMB is detected when (a) a single factor emerges from the factor analysis as the best solution or (b) one general factor accounts for more than $50 \%$ of the covariance among the measures. In our study, we find that the best factor representation is one consisting of four factors and when all the variables load onto a single factor only $35 \%$ of the covariance among the measures is explained. Second, we also tested the potential impact of CMB by using a marker variable (Lindell \& Whitney, 2001). In this test, a marker variable - expected to be dissimilar to the variables in the study - is introduced to the measurement model. CMB is detected when the marker variable significantly covariates with the rest of the latent constructs, suggesting that there is a common source of variance to all the variables that is attributable to the way data were gathered. We introduced the desire for segmentation factor [4-item scale; (Rothbard, Phillips, $\&$ Dumas, 2005); reliability in our sample is .894] and it is only correlated with work-family friendly culture $[\mathrm{r}=$ $-.231, \mathrm{p}<.01]$. This suggests $\mathrm{CMB}$ is not significantly affecting our results; the maximum-shared variance between the variables in the model is $5.34 \%$. In conclusion, the Harman's single factor test and the marker variable procedure show that there is no strong $\mathrm{CMB}$ effect in our model.

\section{Discussion and Conclusion}

The present study examined the relation between family supportive environments in organizations (i.e. FSSB and work-family friendly culture) and turnover intentions. Hypotheses 1 and 2 tested the aspects of the organizational context that engender SWFB. Hypothesis 3 focused on the relation between being satisfied with work-family balance and intentions to leave the workplace. The three hypotheses regarding direct relations were supported. Our findings are consistent with previous research (e.g. Allen, 2001; Behson, 2005; O'Neill et al., 2009) and, furthermore, contribute to the growing literature on the positive aspects of the work-family interface (e.g. Kirchmeyer, 1992; Wayne, Musisca, \& Fleeson, 2004), which has been dominated by the conflicting perspective (Greenhaus \& Beutell, 1985; Greenhaus, Parasuraman, \& Wormley, 1990).

Based on social exchange theory, we proposed a mechanism through which family supportive environments in organizations impact turnover intentions and, therefore, made an important contribution to research on the work-family interface. Hypotheses 4 and 5 tested the mediating role of SWFB and both hypotheses were supported. Balance can be attained when individuals feel that they are effective and satisfied in their higher priority role - that is, either work (career-focused) or family (family-centered) - or in both roles (dual centrality) (Greenhaus \& Allen, 2011). Theoretically, positive aspects of the work-family interface can contribute to work-family balance (Greenhaus \& Allen, 2011). Hence, this study provides evidence that efforts to manage work-family issues do indeed enhance SWFB, which in turn favors employees' sustained employment with the company.

We can draw practical implications from our results. First, our findings advance the understanding of how soft measures produce hard facts; we find that SWFB, our central construct, mediates the relationship between FSSB, work-family friendly culture and turnover intentions. This means that since companies need to justify the value for money of any investment they make, decision-makers should focus on generating SWFB: this soft initiative results in real economic benefits.

Managers, and companies at large, should be aware that employees who have been empowered to decide how to allocate their own resources best (time, energy and attention) are more committed to their jobs. Employees no longer want to be required to divide their attention, energy and time as the organization decides, with no consideration given to their own preferences. Employees have lives and obligations, and companies cannot assume they will push them aside as they work. In fact, software, behaviors, or rules, intended to uncover and punish behaviors that re-balance work and family (e.g. taking personal phone calls at work or responding to personal e-mails) might result in a decreased level of satisfaction and higher turnover.

According to our results, organizations would benefit from customizing and segmenting employees according to their needs, preferences and work, since employees in different age cohorts, of diverse occupational backgrounds, 
and with varied family situations might need different resources to achieve work-family satisfaction, which in turn will lead to the desire to commit to the company. This implication will grow in importance as new generations of digital natives, i.e. those employees who share a common global culture defined less by age than by their experience growing up immersed in digital technology, reach organizations.

Amid a global economic crisis where wages are stagnating or even falling, it is important for companies to find novel ways to increase employee satisfaction and commitment. If organizations are able to show employees that they care by offering them options to manage their work-family interface adequately, employees will in turn respond by increasing their commitment. And this might not require policies, programs or courses but the willingness to acknowledge people's needs and preferences, which may lead to lower costs and - potentially - big gains.

The limitations of this study come from different sources. First, the design of our study and the cross-sectional nature of our data prevent us from making conclusions about causality. For example, although our hypotheses are theoretically derived, our data does not enable us to rule out the possibility that employees with low turnover intentions are more likely to experience SWFB, as they do not face experience stressors related to a job search. Longitudinal data gatherings in quasi-experimental settings where organizations implement work-family friendly cultures and FSSBs are needed in order to test the causal links between the variables involved in our model.

Second, all of our measures are self-reported. The accuracy of self-reported data has been largely discussed in organizational research, emphasizing possible problems of common method bias (e.g. Podsakoff et al., 2003). In our study we statistically assessed the possible presence of inflated correlations due to our data gathering method, finding that common method bias is not a main concern affecting our results.

Third, the interpretation of our findings is constrained by our measure of FSSB. This measure was the first to be developed to evaluate such behaviors; yet, it is not exempt from construct validity issues. In fact, although the scale used in the present study is comprehensive, it does not capture the complete range of behaviors that are needed by employees to balance work and family (see: Hammer et al., 2009). Thus, we are not able to rule out the effect of other supervisor behaviors that may help employees better integrate work and family responsibilities. Future research should focus on developing scales that capture a broader range of FSSB as stronger results could probably emerge from a more reliable and comprehensive measure.

Finally, limitations to the external validity of our results come from a sample of employees belonging to three Argentinian organizations in the service sector. Although the effect is to some extent enhanced by the fact that sampled organizations were multinational, employees were randomly selected, and organizations were located in different parts of the country, ranging from urban to rural areas of Argentina; as a result, caution should be exercised when generalizing our findings. Consequently, more research is needed in other cultural settings for testing our proposed mechanism and for deriving more robust recommendations for managerial practice.

\section{References}

Allen, T. D. (2001). Family supportive work environments: The role of organizational perceptions. Journal of Vocational Behavior, 58, 414-435. http://dx.doi.org/10.1006/jvbe.2000.1774

Barrah, J. L., Schultz, K. S., Baltes, B., \& Stolz, H. E. (2004). Men's and women's eldercare- based work-family conflict: Antecedents and work-related outcome. Fathering, 2, 305-330. http://dx.doi.org/10.3149/fth.0203.305

Batt, R., \& Valcour, P. M. (2003). Human resources practices as predictors of work-family outcomes and employee turnover. Industrial Relations, 42, 189-220. http://dx.doi.org/10.1111/1468-232x.00287

Behson, S. J. (2005). The relative contribution of formal and informal organizational work-family support. Journal of Vocational Behavior, 66, 487-500. http://dx.doi.org/10.1016/j.jvb.2004.02.004

Blair-Loy, M., \& Wharton, A. S. (2004). Organizational commitment and constraints on work-family policy use: Corporate flexibility policies in a global firm. Sociological Perspectives, 47(3), 243-267. http://dx.doi.org/10.1525/sop.2004.47.3.243

Blau, P. M. (1964). Exchange and power in social life. New York, NY: Wiley. http://dx.doi.org/10.2307/2574842

Breaugh, J. A., \& Frye, N. K. (2008). Work-family conflict: The importance of family-friendly employment practices and family-supportive supervisors. Journal of Business and Psychology, 22(4), 345-353. http://dx.doi.org/10.1007/s10869-008-9081-1

Brislin, R. W. (1970). Back-translation for cross-cultural research. Journal of Cross-Cultural Psychology, 1(3), 185-216. http://dx.doi.org/10.1177/135910457000100301 
Brough, P., O'Driscoll, M. P., \& Kalliath, T. J. (2005). The ability of "family friendly" organizational resources to predict work-family conflict and job and family satisfaction. Stress and Health, 21, 223-234. http://dx.doi.org/10.1002/smi.1059

Bruck, C. S., Allen, T. D., \& Spector, P. E. (2002).The relation between work-family conflict and job satisfaction: A finer-grained analysis. Journal of Vocational Behavior, 60, 336-353. http://dx.doi.org/10.1006/jvbe.2001.1836

Casper, W. J., Fox, K. E., Sitzmann, T. M., \& Landy, A. L. (2004). Supervisor referrals to work-family programs. Journal of Occupational Health Psychology, 9, 136-151. http://dx.doi.org/10.1037/1076-8998.9.2.136

Clark, S. C. (2000). Work / Family boarder theory: A new theory of work / family balance. Human Relations, 53, 747-770. http://dx.doi.org/10.1177/0018726700536001

Cropanzano, R., \& Mitchell, M. S. (2005). Social exchange theory: An interdisciplinary review. Journal of Management, 31, 874-900. http://dx.doi.org/10.1177/0149206305279602

Den Dulk, L., \& de Ruijter, J. (2008). Managing work-life policies: Disruption versus dependency arguments. Explaining managerial attitudes towards employee utilization of work-life policies. International Journal of Human Resource Management, 19(7), 1222-1236. http://dx.doi.org/10.1080/09585190802109986

Emerson, R. M. (1976). Social exchange theory. Annual Review of Sociology, 2, 335-362. http://dx.doi.org/10.1146/annurev.so.02.080176.002003

Frye, N. K., \& Breaugh, J. A. (2004). Family-friendly policies, supervisor support, work-family conflict, family-work conflict, and satisfaction: A test of a conceptual model. Journal of Business and Psychology, 19(2), 197-220. http://dx.doi.org/10.1007/s10869-004-0548-4

Gouldner, A. W. (1960). The norm of reciprocity: A preliminary statement. American Sociological Review, 25, 161-178. http://dx.doi.org/10.2307/2092623

Greenhaus, J. H., \& Allen, T. D. (2011). Work-family balance: A review and extension of the literature. In J. C. Quick, \& L. E. Tetrick (Eds.), Handbook of occupational health psychology (pp. 165-183). Washington, DC: American Psychological Association.

Greenhaus, J. H., \& Beutell, N. J. (1985). Sources of conflict between work and family roles. Academy of Management Review, 10(1), 76-88. http://dx.doi.org/10.5465/amr.1985.4277352

Greenhaus, J. H., \& Powell, G. N. (2006). When work and family are allies: a theory of work-family enrichment. Academy of Management Review, 31(1), 72-92. http://dx.doi.org/10.5465/amr.2006.19379625

Greenhaus, J. H., Collins, K. M., \& Shaw, J. D. (2003). The relation between work-family balance and quality of life. Journal of Vocational Behavior, 63, 510-531. http://dx.doi.org/10.1016/s0001-8791(02)00042-8

Greenhaus, J. H., Parasuraman, S., \& Wormley, W. M. (1990). Effects of race on organizational experience, job performance evaluations, and career outcomes. Academy of Management Journal, 33, 64-86. http://dx.doi.org/10.2307/256352

Hammer, L. B., Kossek, E. E., Yragui, N. L., Bodner, T. E., \& Hanson, G. C. (2009). Development and validation of a multidimensional measure of family supportive supervisor behaviors (FSSB). Journal of Management, 35(4), 837-856. http://dx.doi.org/10.1177/0149206308328510

Hammer, L. B., Kossek, E. E., Zimmerman, K., \& Daniels, R. (2007). Clarifying the construct of family-supportive supervisory behaviors (FSSB): A multilevel perspective. In P. L. Perrewé, \& D. C. Ganster (Eds.), Exploring the work and non-work interface (Vol. 6, pp. 165-204). Bingley, UK: Emerald Group Publishing Limited.

Hammer, L. B., Neal, M. B., Newsom, J. T., Brockwood, K. J., \& Colton, C. L. (2005). A longitudinal study of the effects of dual-earner couples' utilization of family friendly workplaces supports on work and family outcomes. Journal of Applied Psychology, 90(4), 799-810. http://dx.doi.org/10.1037/0021-9010.90.4.799

Harzing, A. W., Reiche, B. S., \& Pudelko, M. (2012). Challenges in international survey research: A review with illustrations and suggested solutions for best practice. European Journal of International Management, 5(4). http://dx.doi.org/10.1504/ejim.2013.052090

Homans, C. G. (1958). Social behavior as exchange. American Journal of Sociology, 63, 597-606. http://dx.doi.org/10.1086/222355

Iacobucci, D., Saldanha, N., \& Deng, X. (2007). A meditation on mediation: Evidence that structural equations 
models perform better than regressions. Journal of Consumer Psychology, 17(2), 139-153. http://dx.doi.org/10.1016/s1057-7408(07)70020-7

Kalev, A., Dobbin, F., \& Kelly, E. (2006). Best practices or best guesses? Assessing the efficacy of corporate affirmative action and diversity policies. American Sociological Review, 71(4), 589-617. http://dx.doi.org/10.1177/000312240607100404

Kelly, E. L., \& Kalev, A. (2006). Managing flexible work arrangements in US organizations: Formalized discretion or "a right to ask". Socio-Economic Review, 4(3), 379-416. http://dx.doi.org/10.1093/ser/mwl001

Kirchmeyer, C. (1992). Perceptions of nonwork-to-work spillover: Challenging the common view of conflict ridden domain relationships. Basic and Applied Social Psychology, 13, 231-249. http://dx.doi.org/10.1207/s15324834basp1302_7

Kossek, E. E., Lautsch, B. A., \& Eaton, S. C. (2006). Telecommuting, control, and boundary management: Correlates of policy use and practice, job control, and work-family effectiveness. Journal of Vocational Behavior, 68, 347-467. http://dx.doi.org/10.1016/j.jvb.2005.07.002

Lambert, S. J. (2000). Added benefits: The link between work-life benefits and organizational citizenship behavior. The Academy of Management Journal, 43(5), 801-815. http://dx.doi.org/10.1037/1076-8998.11.2.169

Lapierre, L. M., \& Allen, T. D. (2006). Work-supportive family, family-supportive supervision, use of organizational benefits, and problem-focused coping: Implications for work-family conflict and employee well-being. Journal of Occupational Health Psychology, 11(2), 169-181. http://dx.doi.org/10.1037/1076-8998.11.2.169

Lindell, M. K., \& Whitney, D. J. (2001). Accounting for common method variance in cross-sectional research designs. Journal of Applied Psychology, 86(1), 114-121. http://dx.doi.org/10.1037/0021-9010.86.1.114

Maertz, C. P., Griffeth, R. W., Campbell, M. S., \& Allen, D. G. (2007). The effects of perceived organizational support and perceived supervisor support on employee turnover. Journal of Organizational Behavior, 28(8), 1059-1075. http://dx.doi.org/10.1002/job.472

Matthews, R. A., Mills, M. J., Trout, R. C., \& English, L. (2014). Family-supportive supervisor behaviors, work engagement, and subjective well-being: A contextually dependent mediated process. Journal of Occupational Health Psychology, 19, 168-181. doi: 10.1037/a0036012

McCarthy, A., Cleveland, J. N., Hunter, S., Darcy, C., \& Grady, G. (2013). Employee work-life balance outcomes in Ireland: A multilevel investigation of supervisory support and perceived organizational support. The International Journal of Human Resource Management, 24, 1257-1276. doi:10.1080/09585192.2012.709189

McCarthy, A., Darcy, C., \& Grady, G. (2010). Work-life balance policy and practice: Understanding line manager attitudes and behaviors. Human Resource Management Review, 20(2), 158-167. http://dx.doi.org/10.1016/j.hrmr.2009.12.001

Mennino, S. F., Rubin, B. A., \& Brayfield, A. (2005). Home-to-job and job-to-home spillover: The impact of company policies and workplace culture. The Sociological Quarterly, 46, 107-135. http://dx.doi.org/10.1111/j.1533-8525.2005.00006.x

Odle-Dusseau, H. N., Hammer, L. B., Crain, T. L. \& Bodner, T. E. (2016). The influence of family-supportive supervisor training on employee job performance and attitudes: An organizational work-family intervention. Journal of Occupational Health Psychology, 21(3), 296-30. http://dx.doi.org/10.1037/a0039961

O'Neill, J. W., Harrison, M. M., Cleaveland, J., Almeida, D., Stawski, R., \& Crouter, A. C. (2009). Work-family climate, organizational commitment, and turnover: Multilevel contagion effects of leaders. Journal of Vocational Behavior, 74(1), 18-29. http://dx.doi.org/10.1016/j.jvb.2008.10.004

O'Reilly, C. A., Chatman, J., \& Caldwell, D. F. (1991). People and organizational culture: A profile comparison approach to assessing person-organization fit. Academy of Management Journal, 34(3), 487-516. http://dx.doi.org/10.2307/256404

Pitt-Catsouphes, M., Kossek, E. E., \& Sweet, S. (Eds.). (2006). The work and family handbook: Multi-disciplinary perspectives and approaches. New Jersey, NJ: Lawrence Erlbaum Associates, Inc.

Podsakoff, P. M. (1986). Self-reports in organizational research: Problems and prospects. Journal of Management, 12(4), 531-544. http://dx.doi.org/10.1177/014920638601200408 
Podsakoff, P. M., MacKenzie, S. B., Lee, J. Y., \& Podsakoff, N. P. (2003). Common method biases in behavioral research: A critical review of the literature and recommended remedies. Journal of Applied Psychology, 88(5), 879-903. http://dx.doi.org/10.1037/0021-9010.88.5.879

Poelmans, S., Greenhaus, J. H., \& Las Heras, M. (2013). Expanding the boundaries of work-family research. A vision for the future. London, England: Palgrave. http://dx.doi.org/10.1057/9781137006004

Roehling, P. V., Roehling, M. V., \& Moen, P. (2001). The relationship between work-life policies and practices and employee loyalty: A life course perspective. Journal of Family and Economic, 22(2), 141-170.

Rothbard, N. P., Phillips, K. W., \& Dumas, T. L. (2005). Managing multiple roles: Work-family policies and individuals? Desires for segmentation. Organization Science, 16(3), 243-258. http://dx.doi.org/10.1287/orsc.1050.0124

Ruderman, M. N., Ohlott, P. J., Panzer, K., \& King, S. N. (2002). Benefits of multiple roles for managerial women. Academy of Management Journal, 45(2), 369-386. http://dx.doi.org/10.2307/3069352

Ryan, A. M., \& Kossek, E. E. (2008). Work-life policy implementation: Breaking down or creating barriers to inclusiveness? Human Resource Management, 47(2), 295-310. http://dx.doi.org/10.1002/hrm.20213

Snow, D. L., Swan, S. C., Raghavan, C., Connell, C. M., \& Klein, I. (2003). The relationship of work stressors, coping and social support to psychological symptoms among female secretarial employees. Work \& Stress, 17(3), 241-263. http://dx.doi.org/10.1080/02678370310001625630

Tett, R. P., \& Meyer, J. P. (1993). Job satisfaction, organizational commitment, turnover intention and turnover: Path analyses based on meta-analytic findings. Personnel Psychology, 46, 259-294. http://dx.doi.org/10.1111/j.1744-6570.1993.tb00874.x

Thompson, C. A. (Ed.). (2008). Barriers to the implementation and usage of work-life policies. Cambridge, MA: Cambridge University Press.

Thompson, C. A., Beauvais, L. L., \& Lyness, K. S. (1999). When work-family benefits are not enough: The influence of work-family culture on benefit utilization, organizational attachment, and work-family conflict. Journal of Vocational Behavior, 54(3), 392-415. http://dx.doi.org/10.1006/jvbe.1998.1681

Valcour, P. M. (2007). Work-based resources as moderators of the relationship between work hours and satisfaction with work-family balance. Journal of Applied Psychology, 92(6), 1512-23. http://dx.doi.org/10.1037/0021-9010.92.6.1512

Van Steenbergen, E. F., \& Ellemers, N. (2009). Is managing the work-family interface worthwhile? Benefits for employee health and performance. Journal of Organizational Behavior, 30, 617-642. http://dx.doi.org/10.1002/job.569

Wayne, J. H., Grzywacz, J. G., Carlson, D. S., \& Kacmar, K. M. (2007).Work-family facilitation: A theoretical explanation and model of primary antecedents and consequences. Human Resource Management Review, 17, 63-76. http://dx.doi.org/10.1016/j.hrmr.2007.01.002

Wayne, J. H., Musisca, N., \& Fleeson, W. (2004). Considering the role of personality in the work-family experience: Relationships of the big five to work-family conflict and facilitation. Journal of Vocational Behavior, 64, 108-130. http://dx.doi.org/10.1016/s0001-8791(03)00035-6

\section{Copyrights}

Copyright for this article is retained by the author(s), with first publication rights granted to the journal.

This is an open-access article distributed under the terms and conditions of the Creative Commons Attribution license (http://creativecommons.org/licenses/by/4.0/). 